\title{
Artificial weathering of surfaces from laminated phenol-formaldehyde resin impregnated compressed wood: impact of top veneer type and overlay application
}

\author{
Lars Passauer $^{1}\left[\right.$ Jürgen Schubert ${ }^{1,2} \cdot$ Tino Schulz $^{1} \cdot$ Philipp Flade $^{1} \cdot$ Björn Wei ${ }^{1} \cdot$ Henry Burkhardt $^{1}$
}

Received: 14 November 2019 / Accepted: 8 December 2020 / Published online: 28 February 2021

(c) The Author(s) 2021

\begin{abstract}
Panels from laminated phenol-formaldehyde resin (PF) impregnated and compressed wood (Compreg) with top veneers from European species of beech, maple and white birch were prepared, each without or coated with resin pre-impregnated overlay papers. To clarify the outdoor resistance of Compreg surfaces, long-term artificial weathering experiments were performed. Weather-related color changes, gloss retention and microscopic and surface topographical surface alterations were examined. It has been observed that the application of PF impregnated paper overlays and combinations of them with melamine formaldehyde resin (MF) treated films significantly improved the weather resistance of Compreg surfaces. The extent of UV and moisture-induced surface damages of Compreg has been shown to also be dependent on the veneer types used as surface top layer. Highest surface and color stabilization against weather was achieved providing Compreg with top veneers from maple combined with PF overlays or applying both MF and PF impregnated overlay films as surface finish.
\end{abstract}

\section{Introduction}

Impregnation with thermosetting resins and subsequent hot compression of pre-impregnated wood veneers reaching raw densities up to $1400 \mathrm{~kg} \mathrm{~m}^{-3}$ is an attractive and promising technology to improve strength properties, dimensional stability and durability of laminated wood against decay and weather (Hill 2006; Stamm and Seborg 1955). In Germany, the procedure has been developed and used at an industrial scale since the 1930s to manufacture products under the military coined tradename "Panzerholz" (Thum and Jacobi 1938), also known under the technical term "Kunstharzpressholz" (Kollmann 1942; Küch 1939; Schulte 1938). Similar products called "Compreg" were developed in the US during World War II at the Forest Products Laboratory (Stamm and Seborg 1941). Compreg and similar materials are currently being produced in Germany

Lars Passauer

Lars.Passauer@ihd-dresden.de

1 Dresden Institute of Wood Technology, Institut fuer Holztechnologie Dresden gemeinnuetzige GmbH, Zellescher Weg 24, 01217 Dresden, Germany

2 Dresden University of Cooperative Education, Hans-Grundig-Str. 25, 01307 Dresden, Germany and UK by companies belonging to the Delignit AG group $\left(\right.$ Panzerholz $^{\circledR}$ ), by Roechling KG, Germany (Lignostone ${ }^{\circledR}$, Transfomerwood $^{\circledR}$ ), Pagholz GmbH, Germany (Pagholz ${ }^{\circledR}$ ), in Poland and in different Asian countries.

The manufacture of the respective products is a proven technology based on the following sub-processes. (I) Impregnation of wood veneers, in Europe commonly rotarycut veneers from European beech, with water-soluble lowmolecular phenol-(PF) and rather more rarely melamineformaldehyde (MF) condensation resins. (II) Pre-drying of impregnated veneers at $100-150{ }^{\circ} \mathrm{C}$. (III) Subsequent hot pressing and deformation/densification of pre-treated veneers with pre-crosslinked reactive resins (prepregs) at specific pressures of 10-25 MPa and temperatures of $100-150{ }^{\circ} \mathrm{C}$ to highly compressed laminated wood (Niemz and Wagenführ 2012; Dunky and Niemz 2002; Stamm and Seborg 1955).

The resins applied act as plasticizer, soften the wood cell wall and enable a non-destructive cell wall collapse and fiber deformation while wood is compressed in transverse direction (Shams et al. 2004). Simultaneously, resin condensation, crosslinking and hardening of the resin that previously penetrated into the cell lumen and the wood cell walls occur. Thus, after resin condensation, the densified wood is fixed and dimensionally stabilized (Yano et al. 1997). Resulting characteristics of compressed and impregnated laminated 
wood - in the following referred to as Compreg-are specifically adjustable by varying veneer thickness, layer structure, resin content, resin type, pressure, and pressing temperature (Shams and Yano 2004, 2006, 2011; Shams et al. 2004, 2006). Compreg is used for a wide range of small-scale and industrial applications due to its strength properties comparable to those of steel but with a much lower specific weight (Niemz and Wagenführ 2012; Westin et al. 2009; Kollmann 1955).

Early uses of Compreg were for aircraft parts, propellers, gears, pulleys, loom parts or for musical instruments (Westin et al. 2009). Actually, it is used industrially in tool- and mould-making, as electrical insulation material for transformer constructions and for vehicle constructions like undersides and slapsticks, coil clamping rings, pressure beams, round rods, threaded rods and nuts, and other CNC machined components (Westin et al. 2009; Dunky and Niemz 2002).

Because of the plasticizing effect of low molecular thermosetting resins, Compreg is deformable before resin condensation and hardening is completed. Thus, it can be molded into three-dimensional shapes (Niemz and Wagenführ 2012; Westin et al. 2009). After processing, the natural appearance of wood is largely maintained, and thus Compreg represents an attractive wooden material for representative and decorative applications (Rowell 1999; Seborg 1955). Hence, despite significantly higher costs compared with untreated solid or laminated wood (Kollmann 1955), Compreg application for high-value outdoor applications is rising (Bao et al. 2016; Passauer et al. 2016). Examples of outdoor products are seat shells for stadium seating, cushions for park benches, and façade or landscape-architectural elements that have to be exterior resistant if permanently exposed to weather (Passauer et al. 2016).

Weathering of wood surfaces is well known to cause substantial material and surface alterations such as discoloration (Oberhofnerova et al. 2017), surface roughening and cracking (Reinprecht et al. 2018). There is a large number of studies discussing this phenomenon for native (Evans et al. 1992), thermally (Baysal et al. 2014) or chemically modified wood (Evans et al. 2000) and to a lesser extent for PF or MF resin treated wood (Bicke and Militz 2015; Hansmann et al. 2005). On the other hand, there is a lack of published data regarding weather-related changes in surface properties of Compreg.

Since improvements in physical and mechanical properties due to impregnation and compression of laminated wood is well investigated, weather-related changes in color, microstructure, roughness or other surface properties related to the optical appearance and haptic of Compreg are currently not documented.

Due to the increasing use of Compreg in outdoor applications, knowledge of weathering stability is therefore considered essential, which also is supported by the fact that moisture- and weather-induced damage on exposed Compreg surfaces has been observed in corresponding products after several years of use (Bao et al. 2016; Passauer et al. 2016). Material-related causes of this are to be clarified and technologies developed that delay or at best prevent weatherrelated damage to the Compreg surfaces as long as possible.

Thus, weather-related changes of selected surface properties of Compreg were examined on macroscopic and microscopic levels. Thereby, the focus was on changes in optical and microstructural parameters like color, gloss, surface topographical features and surface roughness induced by artificial weathering. Surface alterations were investigated (a) depending on which type of veneer-European beech, European maple, and European white birch-was used as top layer; (b) depending on which type of resin-low-molecular weight $\mathrm{PF}$ or MF- was applied to top veneer impregnation; and (c) whether PF or MF overlay films or combinations thereof were used as an additional surface finish or not.

\section{Materials and methods}

\subsection{Materials}

Compreg panels were prepared in a pilot plant scale using rotary-sliced veneers from European beech (Fagus sylvatica L., FASY) commonly used for industrial compreg production in Europe (Dunky and Niemz 2002; Kollmann 1955). Veneer dimension was $300 \mathrm{~mm} \times 300 \mathrm{~mm}$ and the thickness was $0.4 \mathrm{~mm}$ for core layers and $0.6 \mathrm{~mm}$ for top veneers. To study a possible influence of the veneer type on the surface properties of Compreg, rotary-sliced veneers from European birch (Betula pendula Roth, BTXX) and sliced veneers from European maple (Acer pseudoplatanus L.; A. platanoides L., ACPL) with the same dimension were used as alternative top layers. Both types of veneer have been described as comparatively easy to impregnate with synthetic resins and can also be used for Compreg production (Westin et al. 2009; Wagenführ 1996; Kollmann 1955). Core and top veneer slides were evaluated visually, and only specimens without defects like knotholes, cracks, or insect holes that may affect the appearance and surface properties of the resulting Compreg panels were selected.

For top and core veneer impregnation, a low-molecular PF condensation resin (resole type, Prefere resins, Germany) with a solids content of $70 \% \pm 2 \%, \mathrm{pH}$ value of $8.5 \pm 0.5$ and viscosity of 300-600 MPa s was used. Alternatively, a MF resin (BASF, Germany) with a pH of 9.8 and viscosity of 45-70 MPa s was used for top veneer treatment if subsequently coated with MF impregnated overlay papers or MF-PF overlay combinations. 
PF and MF resin impregnated cellulose paper overlays were supplied by Surfactor (Germany) and Hans Schmid KG (Germany), respectively.

\subsection{Compreg production and characterization}

Resin impregnation of veneers. Air-dried beech veneers used as core layers were industrially impregnated under normal pressure in a PF resin immersion bath by soaking (Stamm and Seborg 1941, 1955) and pre-dried in a continuous hotair flotation dryer at $100{ }^{\circ} \mathrm{C}$ (processing time: $10 \mathrm{~min}$ ). Impregnation degree of the veneers and resin quantity were adjusted by the feed speed of the conveying sieves, which continuously transported the veneers through the impregnation bath. Top veneers from beech, maple and white birch were resin-impregnated (PF or MF resin) on a laboratory scale by double-sided brush application. In each case, the total resin application amount was $190.0 \pm 10.0 \mathrm{~g} \mathrm{~m}^{-2}$. Subsequently, veneers were pre-dried in a laboratory-drying oven with recirculating air at $95{ }^{\circ} \mathrm{C}$ for $10 \mathrm{~min}$.

Compression of veneer prepregs. Compreg boards were made from 28 core veneers with adjacent layers having a fiber orientation of $90^{\circ}$ to one another. Top and bottom surfaces of uncoated Compreg boards were finished with two parallel oriented top veneers, each from either beech, white birch, or maple. Counterparts were coated additionally with a PF or MF impregnated overlay paper or combinations of both, in the study referred to as PF_O, MF_O or MF/PF_O variants (Fig. 1). Stacked veneers and overlay films were processed at a maximum specific pressure of $120 \mathrm{MPa}$ at $130{ }^{\circ} \mathrm{C}$ to ensure wood softening and densification and simultaneous resin thermosetting. For that purpose, a hydraulic laboratory down-stroke press with re-cooling option (Höfer, Austria) was used. Pressing time at maximum temperature was $2 \mathrm{~min} \mathrm{~mm}^{-1}$. Subsequently, panels were cooled down to $55^{\circ} \mathrm{C}$ while the press was in
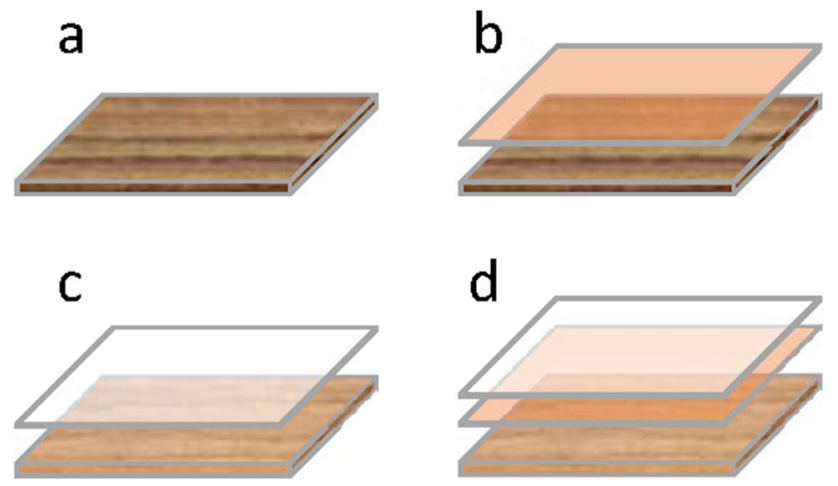

Fig. 1 Surface finish of uncoated and overlay-treated Compreg variants: PF impregnated top veneer without (a) and with PF overlay (b); MF impregnated top veneer with MF overlay (c) and with a combination of MF (top layer) and PF overlays (d) closed position. Compreg panels obtained had a thickness of $10 \mathrm{~mm}$. Compreg characterization. Average density and density profiles of selected specimens were determined by $\mathrm{X}$-ray densitometry based on the principle as explained by Ranta and May (1978) using a density profile analyzer GreCon DA-X (GreCon, Germany).

\subsection{Artificial weathering}

Compreg belongs to the material group of (high-pressure) laminates (Niemz and Wagenführ 2012) and is therefore tested for its weathering stability in the same way as HPL (EN 438-2 2016). Consequently, artificial weathering of Compreg specimens with a dimension of $145 \mathrm{~mm} \times 65 \mathrm{~mm}$ $\times 10 \mathrm{~mm}$ was accomplished according to EN ISO 4892-2 (2013), method A, cycle 1 (102 min dry, 18 min spray water) using a Weather-Ometer ATLAS Ci3000 (Atlas Material Testing Technology, USA). To simulate the relative irradiance of solar radiation in the UV and visible spectral region, the weathering device is equipped with a watercooled xenon arc lamp. The following weathering conditions were adjusted: irradiance $\mathrm{E}_{300-400}=60 \pm 2 \mathrm{~W} \mathrm{~m}^{-2}$, black panel temperature $\mathrm{BCT}=65 \pm 2{ }^{\circ} \mathrm{C}$, and relative humidity $50 \pm 10 \%$. Total exposure time $\mathrm{t}_{\exp }$ was $1000 \mathrm{~h}$. Unexposed and artificially weathered surfaces of the specimens were characterized as described in the following sections.

\subsection{Reflectometry and colorimetry}

Gloss measurements were taken according to EN ISO 2813 (2014) using a portable gloss-meter REFO 3D (HachLange, Germany) with a three-angle geometry at $60^{\circ}$ and $85^{\circ}$, respectively. CIELab color changes were determined as described in ISO 11664-4 (2008) using a spectrophotometer CM-3610d (Minolta, Japan) under the following conditions: d65 standard light, $10^{\circ}$ standard observer with gloss trap, measuring point $\varnothing: 24.5 \mathrm{~mm}$. The reflection spectra were acquired in the spectral range between 360 and $740 \mathrm{~nm}$. CIE color parameters $\mathrm{L}^{*}$ (lightness), $\mathrm{a}^{*}$ (red-green axis) and $\mathrm{b}^{*}$ (yellow-blue axis) were calculated from the spectra using the spectrophotometer software SpectraMagic NX. Color differences expressed as $\Delta \mathrm{E}^{*}$ were computed according to Eq. (1).

$\Delta E^{*}=\sqrt{\left(\Delta L^{*}\right)^{2}+\left(\Delta a^{*}\right)^{2}+\left(\Delta b^{*}\right)^{2}}$

Both gloss and color measurements were taken at two precisely defined points of the unexposed sample surface $\left(t_{\exp }=0 \mathrm{~h}\right)$ and after exposure times $\mathrm{t}_{\exp }=250,500,750$ and $1000 \mathrm{~h}$, respectively. Thus, changes in color and gloss were always monitored within the same surface spots. 


\subsection{Light microscopy}

Cross-sections of veneers before and after PF impregnation of a finished Compreg board, as well as exactly defined surface spots of selected Compreg samples before and after 250, 500, and $1000 \mathrm{~h}$ of exposure were investigated with an incident light microscope SMZ 1500 (Nikon, Japan) and with an incident light fluorescence microscope ECLIPSE E 800 (Nikon, Japan) under UV light. Images were prepared using the image processing system NIS Elements D3.2 and a digital camera DS-Fi1c.

\subsection{Confocal laser scanning microscopy}

Confocal laser scanning microscopy (CLSM) combines high-resolution optical imaging with depth selectivity, which allows performing optical sectioning and the detection of surface topographical features of the sample. Therefore, multiple 2D images (horizontal scanning) at different depths in a sample are captured. In the course of this, only light from the focal plane is collected while rejecting the out of focus light. These 2D images can be used to compute a 3D model of the sample surface.

For this study a confocal laser scanning microscope Leica SP8 was used to analyse morphology and topographic features of selected samples. A $488 \mathrm{~nm}$ solidstate laser (maximum laser output power: $20 \mathrm{~mW}$ ) was employed as light source. Surface areas of $2000 \mu \mathrm{m} \times$ $2000 \mu \mathrm{m}$ were scanned using a $20 \times$-objective. Surface scans were conducted threefold for each specimen.

With the samples being moved along the optical axis by defined increments of $0.68 \mu \mathrm{m}$, multiple images were recorded at different $Z$-planes at each scanning area of the specimens. Using Fuji image processing software (Schindelin et al. 2012), a heightmap of the sample surface was computed in which the intensity in each pixel represented the total amount of backscattered light and thus the height on the surface of the sample in $\mu \mathrm{m}$. With the help of the heightmap, the roughness was calculated using the SurfCharJ1q Plug-in in Fuji. Roughness should deliver information regarding weather-related microstructuring of the material's surface (Faucheu et al. 2006) and is expressed as follows:

(I) By the arithmetic average roughness $R_{a}$ :

$$
R_{a}=\frac{1}{n} \sum_{i=1}^{n}\left|z_{i}\right|
$$

where $z_{i}$ is the vertical distance from the mean line to the $i$ th data point.

(II) The root mean squared roughness $R_{q}$ :

$$
R_{q}=\sqrt{\frac{1}{n} \sum_{i=1}^{n} z_{i}^{2}}
$$

(III) The maximum height of the profile $\mathrm{R}_{\mathrm{t}}$ :

$R_{t}=R_{p}-R_{v}$

where the maximum valley depth $R_{v}=\min _{i} z_{i}$ and maximum peak height $R_{p}=\max _{i} z_{i}$.

\section{Results and discussion}

\subsection{General considerations}

In the current work, Compreg was made using core layer veneers from beech, which were industrially impregnated by immersion. Top veneers from beech, maple and white birch were treated alternatively by manual brush application of low-molecular PF or MF resins. In this state-the so-called A-stage- the aqueous impregnation resins contain low molecular oligomers and have therefore a low viscosity and correspondingly a high penetration capability (Biziks et al. 2019; Thebault et al. 2017). By means of microscopic imaging of the cross-sectional areas of impregnated and pre-dried beech veneers, it becomes evident that both types of impregnation have comparable effects regarding applied resin quantity and resin penetration depth (between 50 and $100 \mu \mathrm{m}$ ) into the veneer (Fig. 2a, b). The type of impregnation should therefore not affect top veneer processing and material/surface characteristics of the resulting Compreg variants. Identical raw density profiles of variants processed with an industrial PF impregnated top veneer and a manually treated counterpart as top layer support this assumption (Fig. 3). The resulting average raw density of the samples was $1375 \mathrm{~kg} \mathrm{~m}^{-3}$.

Figure 2 also depicts a stack of impregnated and pre-dried beech veneers, a resulting Compreg sample manufactured on a laboratory scale (c, d) and a cross-sectional area of the specimen with the typical multilayer design of the material (e). The multilayer structure also becomes visible in the wave-like raw density profile with density peaks around $1410 \mathrm{~kg} \mathrm{~m}^{-3}$ and local minima about $1325 \mathrm{~kg} \mathrm{~m}^{-3}$ (Fig. 3).

The micrograph of the cross-sectional area of the hotcompressed sample under UV light revealed that the wood vessels were completely filled with resin during wood processing (Fig. 2f, blue fluorescing areas). This condition ensures a sufficient and strong interaction between the resin and the wood matrix and thus an adequate cell wall softening, wood deformation and adhesion between the veneer prepregs. Due to heating and fusing of the resin in the B-stage, cell wall softening and subsequent material densification, the morphology of the compressed wood changed 

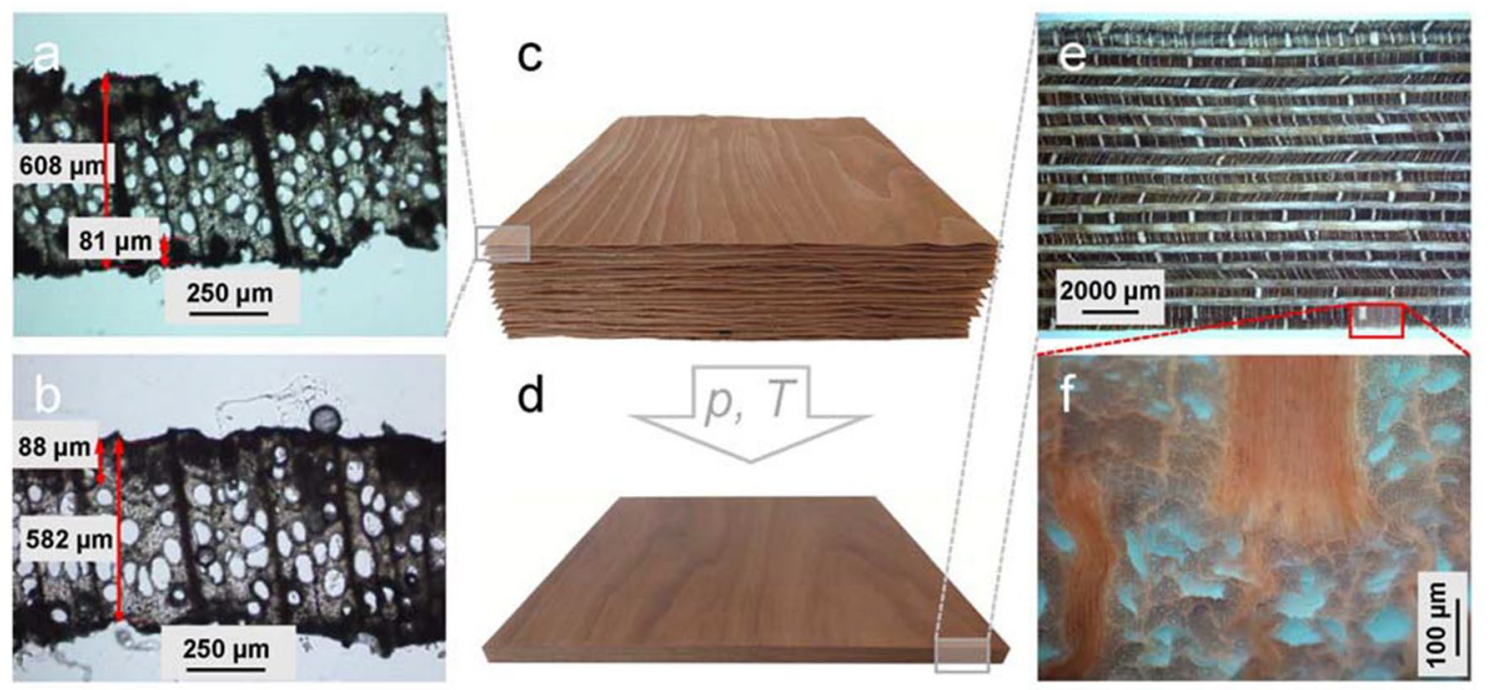

Fig. 2 Cross-sections of beech veneers after $\mathbf{a}$ industrial and $\mathbf{b}$ manual PF resin impregnation and pre-drying. Arrows indicate veneer thicknesses and resin penetration depths. Stacked PF impregnated

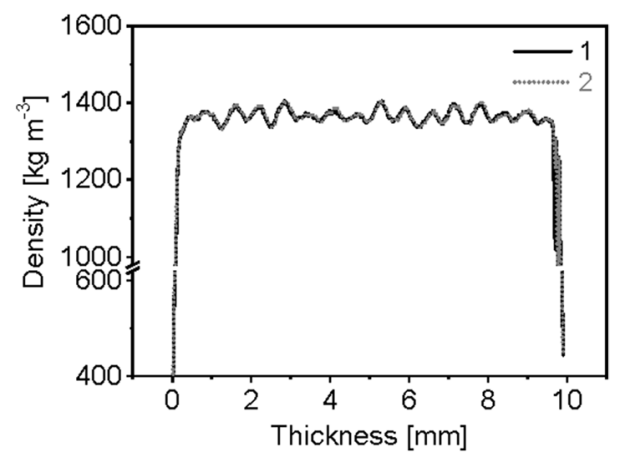

Fig. 3 Density profiles of Compreg with top veneers that were either industrially (1, black line) or manually impregnated with PF (2, dotted line)

significantly compared with its original state (Fig. 2a, b). It is evident that circular and oval pores became irregularly shaped, vessel lumen volume decreased, and rays became undulating due to compression (Fig. 2f). Similar effects were recently described for Compreg based on hardwoods like poplar and beech (Bao et al. 2016; Gabrielli and Kamke 2010; Küch 1951).

\subsection{Weather-related changes in appearance and CIELab color parameters}

In the current study, artificial weathering was performed according to EN ISO 4892-2. In that context, the aim was not to simulate natural weathering in a specific local region, but the defined changes between dry and spray water intervals beech veneers $\mathbf{c}$ before and $\mathbf{d}$ after hot compression. e Micrograph of the cross-section of a Compreg panel (scale 7.5:1) and f zoom into a cross-sectional area under UV light (scale 200:1)

have served to induce a hard and cyclic stress to the tested specimens and an accelerated surface ageing. Furthermore, the periodical water spray ensures the removal of degraded material from the sample surface as is the case under realistic conditions during rainfall events in natural weathering tests or practical outdoor exposure (Hansmann et al. 2005).

Figure 4 shows the surfaces of Compreg samples with top veneers from (a) beech, (b) maple, and (c) white birch each without an overlay, with PF or MF impregnated overlay films, and combinations thereof (not for white birch) after the samples have been exposed to artificial weathering over a period of $1000 \mathrm{~h}$.

It is obvious that Compreg surfaces without protective overlays strongly brightened up compared to the initial state that is characterized by a strong reddish-brown color (unexposed peripherical areas of test specimens and scaled down images bottom right in Fig. 4), regardless of which type of veneer was used. This original color is substantially caused by the phenolic resin, more precisely quinoid compounds like quinone methides that are formed by the oxidation of phenols during the synthesis and the processing of PF resins (Pilato 2008).

It is noteworthy that the considerable color change is not only due to the moisture- and light-induced wood discoloration that is discussed extensively in the literature (Passauer et al. 2015; Hon and Minemura 2001). A key reason is the degradation and damage of the phenolic resin surface of Compreg connected with embrittlement, microcracking and subsequent stress whitening. The phenomenon was most distinct for the sample with beech surface (Fig. 4a, FASY) and will be discussed in Sect. 3.3 in more detail. 


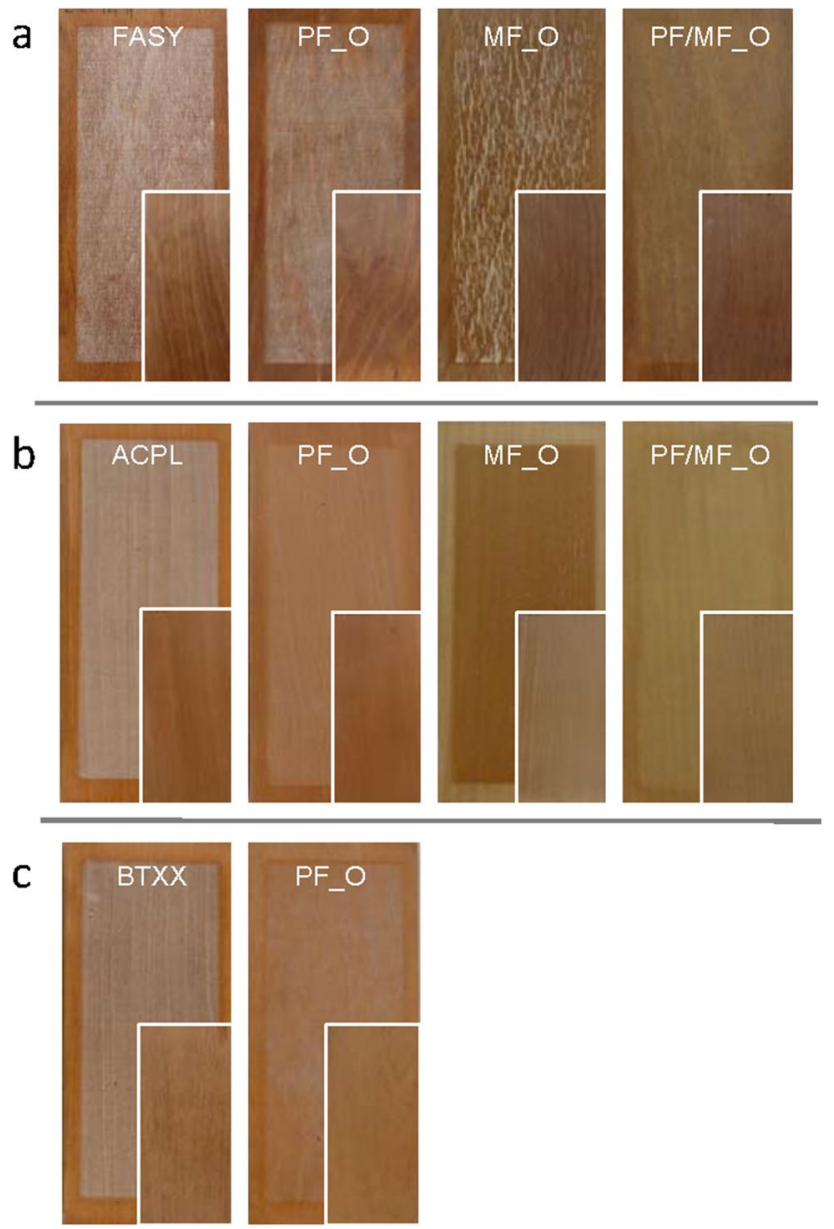

Fig. 4 Compreg surfaces before (scaled down images in each case bottom right) and after $1000 \mathrm{~h}$ of exposure. Samples with top veneers from a European beech (FASY), b European maple (ACPL) and c European white birch (BTXX) each without overlay application, variants with $\mathrm{PF}$ (PF_O) and MF pre-impregnated overlays (MF_O) and combinations thereof (MF/PF_O)

This brightening effect was less pronounced for all Compreg types in case of applying a PF impregnated overlay paper. The protective and color stabilizing effect of the phenol film is particularly impressive for the variant with maple top veneer (Fig. 4b, ACPL_PF_O). Promising results were also obtained for BTXX_PF_O (Fig. 4c). Because of the comparable behavior of these two variants, further treatments with MF overlays and MF/PF film combinations were performed regardless of BTXX variants.

Alternatively, stabilization against weather without surface damaging was achieved applying maple top veneers in combination with melamine overlays (Fig. 4b, ACPL MF_O). Because both overlay and top veneer were treated with transparent MF resins, the starting color of the sample was much brighter than that of the counterparts treated with PF. Thus, artificial weathering of ACPL_MF_O led to severe darkening of the sample surface. This is probably due to the UV transparency of the MF film and a more intense photooxidation of UV sensitive wood components such as lignin and low molecular phenolic wood extractives (Passauer et al. 2015; Hon and Minemura 2001). Compared with ACPL_MF_O, the counterpart with beech top veneer (FASY_MF_O) exhibited a higher susceptibility to surface damaging and whitening that manifests in a reticular white flecked damage pattern (Fig. 4a). Combined application of a MF overlay (topcoat) and a PF film (subjacent layer) resulted in a more considerable surface stabilization without cracking and only minor discoloration and brightening for both, samples with beech and maple top veneers (FASY_MF/PF_O, BTXX_MF/PF_O).

Figure 5 depicts the CIELab color changes of the respective Compreg variants including the progress of the total color change $\Delta \mathrm{E}^{*}$ during artificial weathering (Fig. 5a-c) and shifts of lightness $\Delta \mathrm{L}^{*}$, red-green components $\Delta \mathrm{a}^{*}$ and blue-yellow axis $\Delta b^{*}$ after the maximum exposure time of 1000 h (Fig. 5e-f).

For untreated samples, a rapid discoloration-indicated by the significant total color change $\Delta \mathrm{E}^{*}$-was observed after $250 \mathrm{~h}$ of weathering. This is particularly true for specimens with top veneers from beech and birch and less pronounced for the sample with maple surface (Fig. 5a-c). Successively declining rates of discoloration for untreated variants ACPL and BTXX are probably due to a rapid initial darkening of the originally brightly colored veneer surfaces in the early stage of exposure $\left(\mathrm{t}_{\exp }=250 \mathrm{~h}\right)$ and subsequent whitening of the pre-damaged phenolic resin surface. Later on, at $\mathrm{t}_{\exp }>750 \mathrm{~h}$, resin whitening dominates initial wood darkening and, hence, total color change increases again.

For all untreated sample surfaces, brightening was associated with strong shifts to green $(\Delta \mathrm{a}<0)$ and blue tones $(\Delta \mathrm{b}<0)$ and decreased in the range FASY $>$ ACPL $>$ BTXX with $\Delta \mathrm{L}_{1000 \mathrm{~h}}=23.5,10.7$ and 1.4 (Fig. 5e, f).

Phenol film application significantly reduced total color changes from $\Delta \mathrm{E}^{*}{ }_{1000 \mathrm{~h}}=25.6$ (FASY), 17.7 (ACPL), and 9.6 (BTXX) of uncoated samples to values in the range between 3.8 (BTXX_PF_O) and 10.2 (FASY_PF_O). In case of combining top veneers from beech with PF_O, the general discoloration pattern-brightening with green and blue shift-remained. PF_O-treatment of ACPL markedly reduced the blue shift $\left(\Delta \mathrm{b}^{*}=0.2\right)$ and treatment of BTXX resulted in a slightly increased red value $\left(\Delta \mathrm{a}^{*}=1.8\right)$.

Coating of FASY with a melamine overlay (MF_O) further reduced CIELab color changes but induced surface damaging due to crack formation (cf. Fig. 4a). For ACPL, this kind of treatment led to surface darkening $\left(\Delta \mathrm{L}^{*}=-6.3\right)$ associated with a red shift $\left(\Delta \mathrm{a}^{*}=4.4\right)$ and surface yellowing $\left(\Delta b^{*}=4.7\right)$. Samples with top veneers from beech (FASY MF/PF_O) and maple (ACPL_MF/PF_O) that were treated with combinations of melamine (top layer) and phenol films ("underlay") behaved similar to PF_O coated counterparts. 
Fig. 5 Progress of the weatherinduced total color change of Compreg surfaces with top veneers from a European beech (FASY), b European maple (ACPL) and $\mathbf{c}$ European white birch (BTXX) without or with PF (PF_O) or MF overlays (MF_O) and combinations thereof (MF/PF_O). CIELab color changes of respective samples after $1000 \mathrm{~h}$ of exposure $(\mathbf{d}-\mathbf{f})$
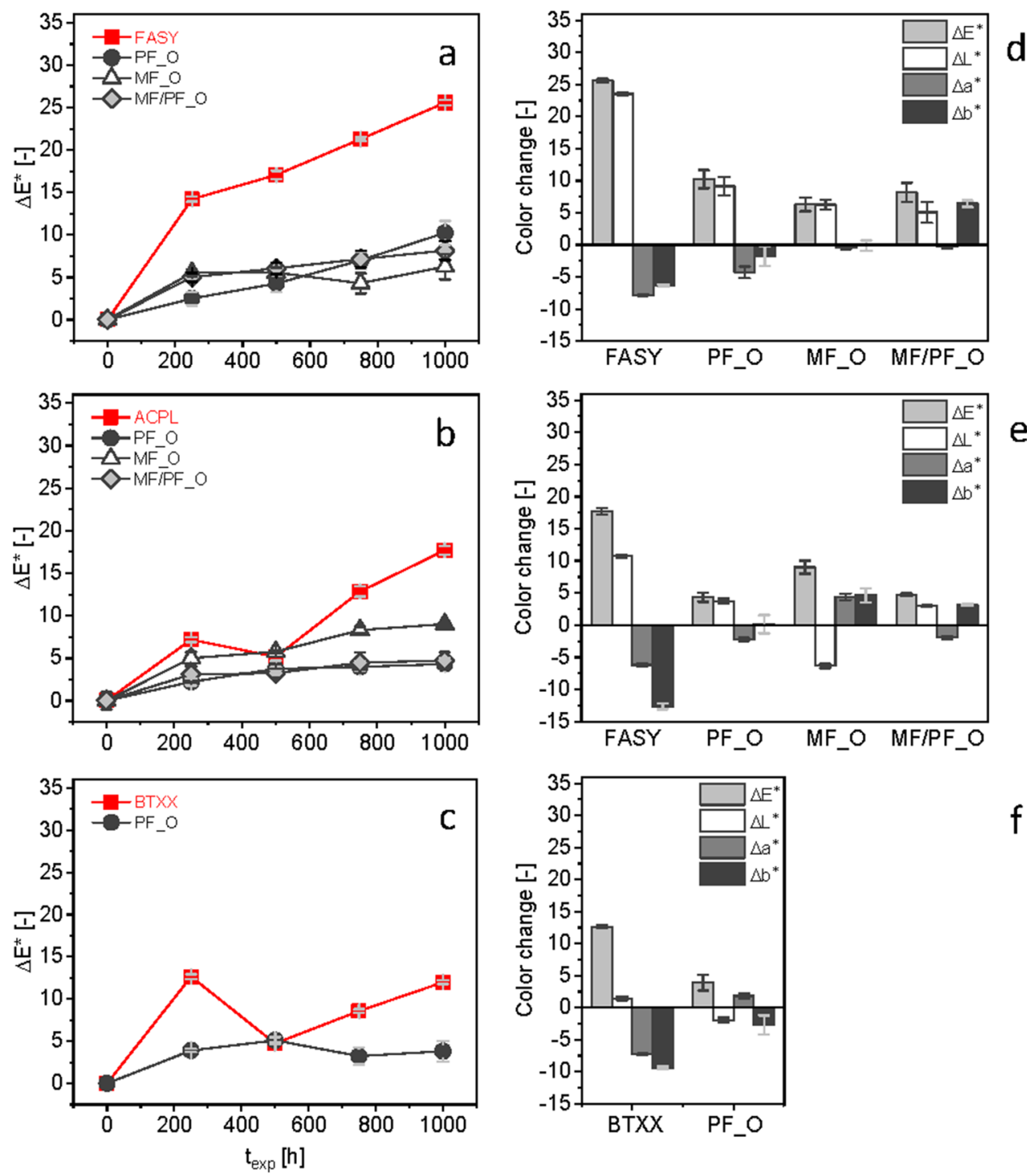

Different from PF_O variants, they exhibited slight yellowing that is more pronounced for the sample with top veneer from beech $\left(\Delta b^{*}=6.4\right.$ and 3.2).

\subsection{Microstructural alterations and changes in gloss}

Weather-related microstructural changes of Compreg surfaces including surface roughening and crack formation were analyzed using light microscopy. Figure 6 depicts defined surface sections of Compreg variants with top layers from European beech and European maple without and with PF treated overlays after different times of exposure. It became obvious that progressive cracking at the surface of Compreg with top veneers from beech took place particularly within the wood rays in longitudinal direction. It was associated with a gradual erosion of the resin from the surface and subsequent surface bleaching (Fig. 6a-c).
The resin degradation is probably initiated by the photooxidation of UV absorbing phenolic structures of the resin and subsequent resin embrittlement by interchain cross-linking between free radicals in adjacent chains, formed after induced resin photolysis (Rabek 1995; Rivaton and Lemaire 1989). Susceptibility to crack formation of ACPL was much lower (Fig. 6g-i) and markedly reduced for both types of Compreg providing PF overlays. Nevertheless, microcracks appeared at the overlay of FASY_PF_O, originating again from wood rays (Fig. 6d-f). The results emphasize that particularly large wood rays - as is the case for beech woodare prone to cracking and serving as potential fissure channels during wood drying or alternating climatic or moisture conditions as explained by Richter (2014). Furthermore, the uncovering of cellulosic fibers of the overlay paper that is a result of resin embrittlement and subsequent resin erosion from the overlay surface additionally contributes to surface whitening of this Compreg variant. At the surface 
Fig. 6 Micrographs of the surface of Compreg variants with top layers from European beech (a-f) and European maple (g-l) without $(\mathbf{a}-\mathbf{c}, \mathbf{g}-\mathbf{i})$ and with $\mathrm{PF}$ overlay $(\mathbf{d}-\mathbf{f}, \mathbf{j}-\mathbf{l})$ after 250,500 and $1000 \mathrm{~h}$ artificial weathering (from left to right); scale bars represent $500 \mu \mathrm{m}$
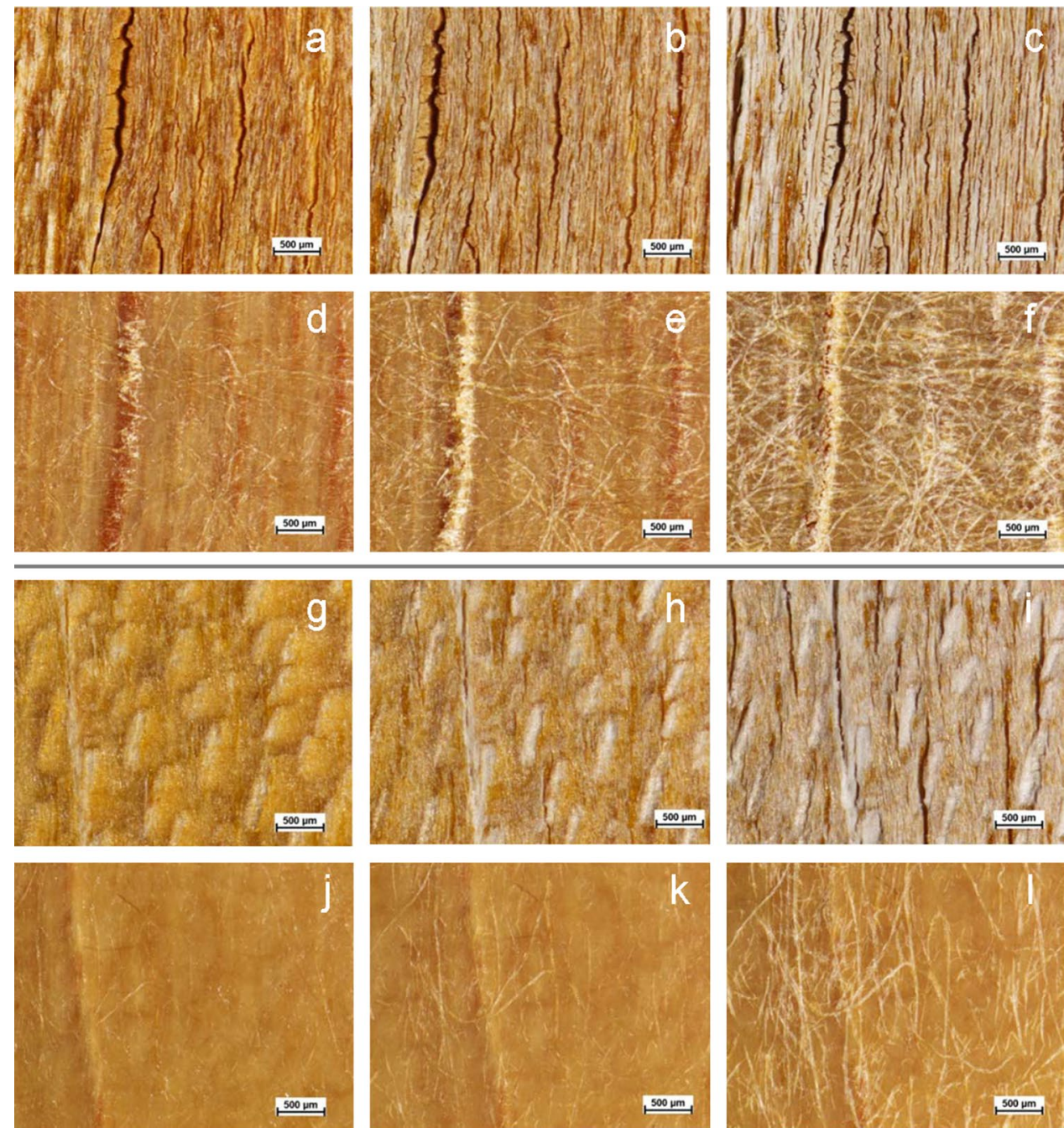

of ACPL_PF_O, this phenomenon is strongly decreased meaning that no cracks have been generated and only a few uncovered cellulosic fibers at the exposed overlay surface became visible (Fig. 6k, l).

The weather-related increase in surface microstructuring includes an increase in light scattering and results in a successively diminished gloss degree. The phenomenon was extensively studied in the area of coating materials and is used to assess the outdoor performance of coating systems (Faucheu et al. 2006; Osterhold and Glöckner 2001). Similarly, changes in gloss levels should provide essential information regarding the weather resistance and outdoor performance of Compreg surfaces.

Figure 7 exemplarily depicts the stages of gloss of FASY and overlay-treated counterparts.

Generally, unexposed Compreg variants without overlay films possess matt surfaces with gloss values $<10 \mathrm{GU}$. Overlay application results in somewhat higher gloss levels in the range between 10 and $15 \mathrm{GU}$ (FASY) up to $25 \mathrm{GU}$ (ACPL; not shown). Higher gloss levels of ACPL variants

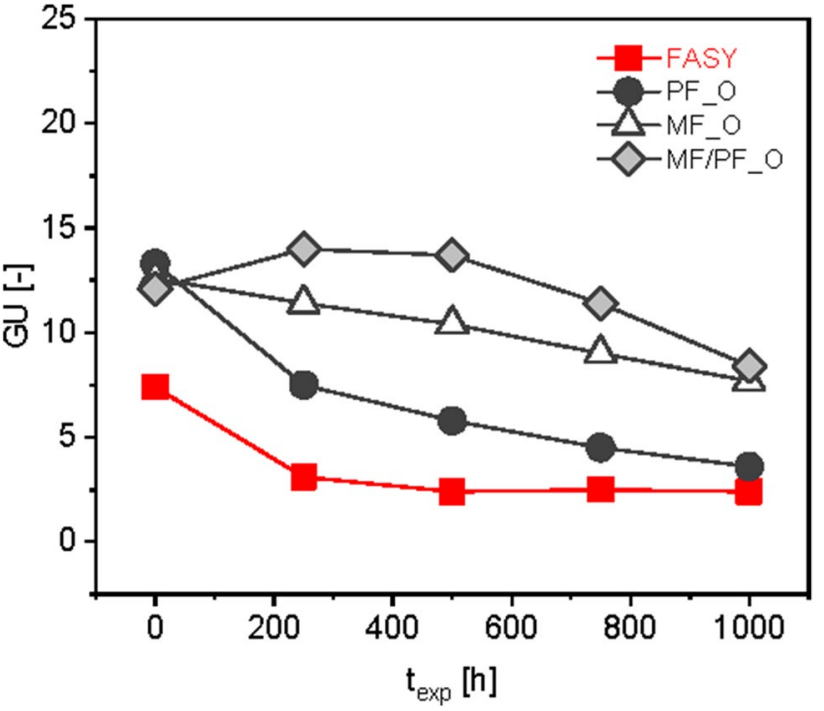

Fig. 7 Changes in gloss levels of Compreg surfaces with top veneers from beech without (FASY) and with PF (PF_O) or MF overlay finish (MF_O), or a MF/PF overlay combination (MF/PF_O) 
are probably due to the specific veneer texture and the appearance of silvery shining wood rays. It is obvious that the gloss level of FASY is heavily reduced after $250 \mathrm{~h}$ of weathering and reached its minimum after $500 \mathrm{~h}(2.40 \mathrm{GU})$. This state corresponds to the point, where the PF resin is almost completely eroded from the top surface of the sample and crack formation is completed substantially as it was shown by microscopy (cf. Fig. 5a, b). The counterpart with PF overlay exhibits a comparable gloss reduction after short time weathering originating from 13.3 (unexposed) to 7.5 $\mathrm{GU}$ after $250 \mathrm{~h}$ and a subsequent and successive decrease down to $3.6 \mathrm{GU}$ after $1000 \mathrm{~h}$. This is mainly a result of the formation of microcracks at the surface and within the overlay finish and subsequently induced the uncovering of white appearing cellulosic fibers at the overlay surface.

This ultimately led to the white stress phenomenon particularly in the region of overlaid wood rays (Fig. 6e, f). A markedly increased gloss retention with final values of 7.7 and $8.4 \mathrm{GU}$ indicates a significantly improved weather resistance of the samples treated with MF and MF/PF film combinations. Furthermore the latter showed a temporary glossing over a weathering period between 250 and $500 \mathrm{~h}$. Respective variants are largely free of cracks after $1000 \mathrm{~h}$ of exposure, which indicates the significantly improved weather resistance of the respective variants (cf. Fig. 4a, b).

\subsection{Relating discoloration and gloss retention}

Correlating gloss levels and total color change of varying Compreg samples impressively summarizes the findings discussed in the previous sections (Fig. 8). Since samples without overlay films markedly change their surface color, reaching maximum color differences $\Delta \mathrm{E}^{*}>25$ in case of FASY (Fig. 8a), the use of PF overlays significantly reduced surface discoloration of all counterparts down to values between 5 and 10, with the lowest discoloration in case of using maple top veneer (Fig. 8b). Simultaneously, gloss reduction was more pronounced if PF films were applied generating medium gloss surfaces in the initial state (13-25 GU). In that context, it has to be considered that specimens without an overlay possessed low gloss surfaces in the initial state and, thus, heavy gloss reduction is physically impossible. Nevertheless, the respective samples were characterized by a rapid gloss reduction after the early stage of exposure.

Application of MF overlays to specimens with top veneers from maple significantly reduced surface microstructuring and, thus, weather-related gloss reduction (minimum $>10 \mathrm{GU}$ ) but led to stronger surface discoloration by light-induced darkening (Fig. 8c). More promising results characterized by simultaneous color and surface stabilization were obtained combining both MF and PF (Fig. 8c). It is assumed that interpenetrating networks that are formed when PF and MF overlays were combined, simultaneously
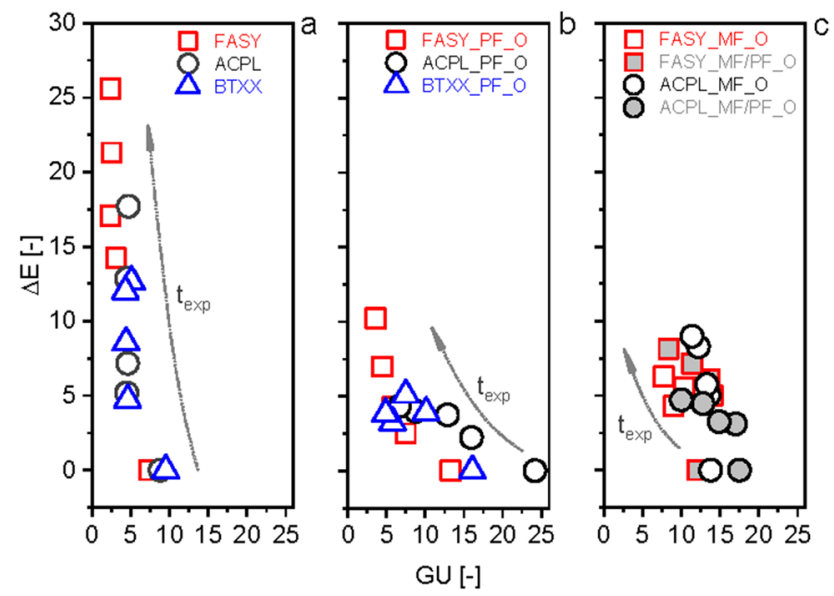

Fig. 8 Correlation between gloss levels and total color change of a Compreg variants with top veneers from beech (FASY), maple (ACPL) and white birch (BTXX), counterparts with b PF and $\mathbf{c}$ MF overlays and MF/PF overlay combinations; arrows indicate development over time of exposure $t_{\exp }$

arise advantages of both resin types like mechanical and chemical resistance (PF, MF), weather and UV resistance (MF), UV protection (PF) and lower brittleness (MF; Evans et al. 2013; Pizzi 2003).

\subsection{Surface topographical alterations}

In connection with surface degradation and associated microstructuring, the quantification and assessment of surface topographical features of related samples can provide important information regarding their weather resistance and surface stability. For that purpose, CLSM was used to characterize selected Compreg samples at their initial state and after maximum exposure time $t_{\exp }=1000 \mathrm{~h}$. Changes in the surface topography after exposure were evident on the microscopic level, as shown in the 2D heightmaps of surface sections of FASY, ACPL and respective variants with PF overlay (Fig. 9).

Unlike the images of the Compreg surfaces before weathering, heightmaps of the exposed sample of FASY showed numerous intensive dark colored areas that are indicative for deep surface valleys. These regions are associated with typical microcracks with parallel fiber orientation (Fig. 9a). Cracking and microstructuring of ACPL seems to be much lower (Fig. 9c), which corresponds to results of light microscopy (cf. Fig. 6). Crack formation and appearance of raised regions (bright areas) due to cyclic moisture and dryness induced swelling and shrinking of wooden rays and wood fibers are markedly reduced for both types of Compreg providing PF overlays (Fig. 9b, d). Nevertheless, FASY_PF_O surface is more structured due to raised cellulosic fibers originating from the overlay film stressed by weather 
Fig. 9 CLSM 2D heightmaps of surface sections of a FASY, b FASY_PF_O, c ACPL, and d ACPL_PF_O before (small images) and after $1000 \mathrm{~h}$ artificial weathering; white bars indicate a distance of $500 \mu \mathrm{m}$; colour tone indicates the height in $\mu \mathrm{m}$ (scale bar; light: $+100 \mu \mathrm{m}$, dark: $-100 \mu \mathrm{m})$
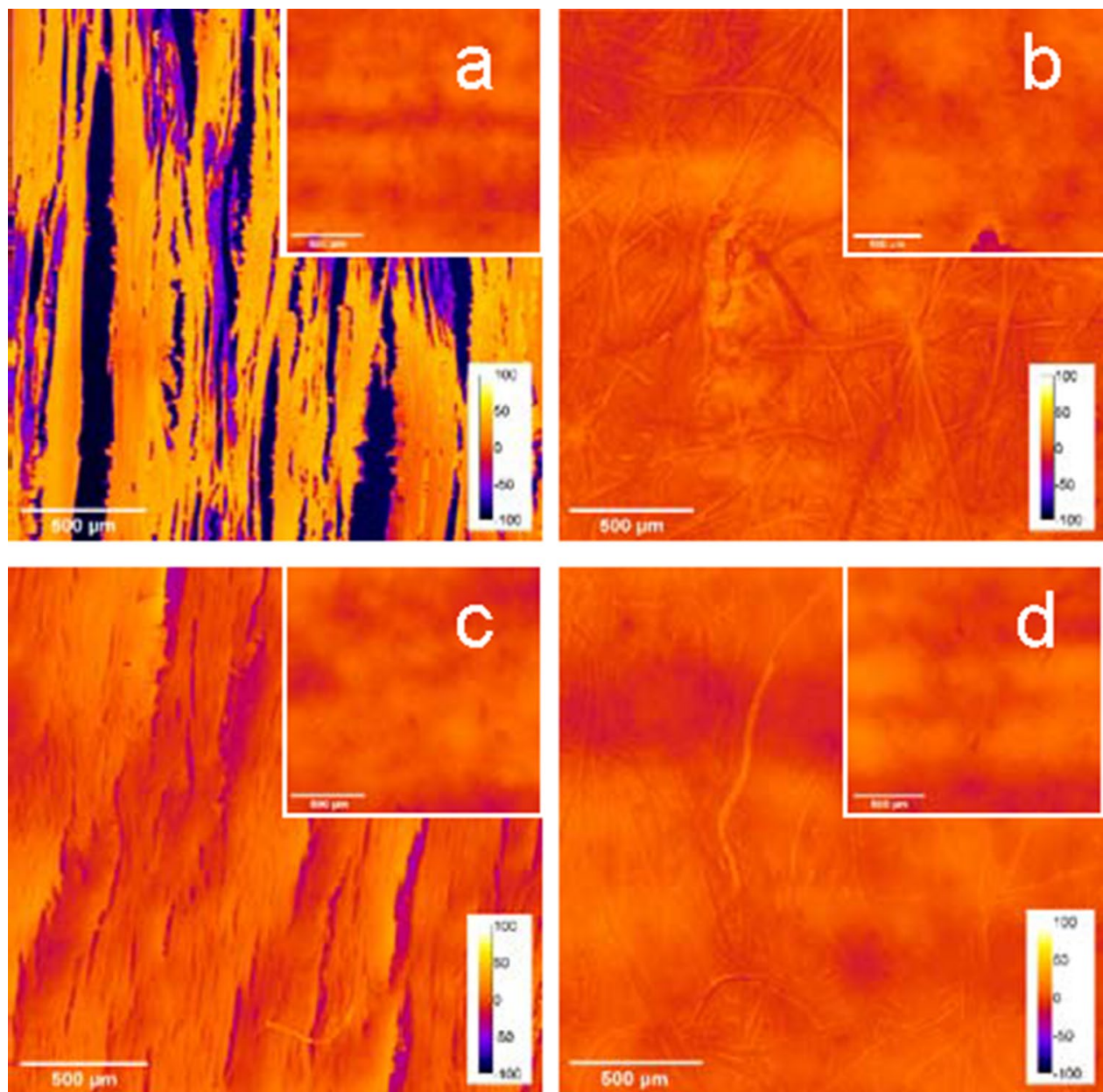

conditions than the equivalent with maple top veneer. This is also consistent with results of light microscopy (cf. Fig. 6) and indicates that the stress level of the overlay film strongly depends on which veneer or wood type-prone to cracking or stable-was applied as surface layer.

Root mean square surface roughness $R_{q}$ of unexposed samples was in the range from 4.04 to $5.63 \mu \mathrm{m}$ with deepest valleys between 13.92 and $22.08 \mu \mathrm{m}$ and highest peaks from 11.11 to $28.31 \mu \mathrm{m}$ (Table 1). Tenfold increase in $R_{q}$ after maximum exposure from 4.83 to $41.45 \mu \mathrm{m}$ and tripling of the maximum height of the profile from $R_{t}=45.72$ to $143.24 \mu \mathrm{m}$ strongly indicated the progression of surface damaging, resin erosion and surface cracking of FASY. In contrast, weather-related surface roughening of ACPL was clearly weaker with $R_{q}$ values rising from 3.86 to $8.99 \mu \mathrm{m}$ and increasing $R_{t}$ from 26.36 to $74.04 \mu \mathrm{m}$, respectively,
Table 1 Surface roughness parameters of Compreg variants before and after artificial weathering $\left(\mathrm{t}_{\exp }=1000 \mathrm{~h}\right)$ : arithmetic mean roughness $R_{a}$, root mean square roughness $R_{q}$, deepest valley $R_{v}$, highest peak $R_{p}$ and highest total profile height $R_{t}$

\begin{tabular}{lccllr}
\hline & $R_{a}[\mu \mathrm{m}]$ & $R_{q}[\mu \mathrm{m}]$ & $R_{v}[\mu \mathrm{m}]$ & $R_{p}[\mu \mathrm{m}]$ & \multicolumn{1}{l}{$R_{t}[\mu \mathrm{m}]$} \\
\hline Unexposed & & & & & \\
FASY & $4.84 \pm 0.35$ & $4.83 \pm 0.35$ & $-17.52 \pm 21.10$ & $28.21 \pm 13.42$ & $45.72 \pm 11.44$ \\
FASY_PF_O & $3.28 \pm 0.39$ & $4.04 \pm 0.48$ & $-17.31 \pm 5.02$ & $11.22 \pm 0.32$ & $28.52 \pm 5.32$ \\
ACPL & $3.83 \pm 0.93$ & $4.67 \pm 1.10$ & $-13.92 \pm 1.97$ & $12.44 \pm 2.33$ & $26.36 \pm 4.28$ \\
ACPL_PF_O & $4.47 \pm 0.53$ & $5.63 \pm 0.51$ & $-22.08 \pm 8.78$ & $15.56 \pm 1.79$ & $37.33 \pm 0.61$ \\
texp =1000h & & & & & \\
FASY & $35.02 \pm 7.71$ & $41.54 \pm 7.41$ & $-84.35 \pm 10.78$ & $58.89 \pm 9.25$ & $143.24 \pm 1.56$ \\
FASY_PF_O & $5.34 \pm 0.70$ & $6.67 \pm 0.87$ & $-26.31 \pm 3.14$ & $21.13 \pm 4.12$ & $47.44 \pm 6.91$ \\
ACPL & $6.84 \pm 0.86$ & $8.99 \pm 1.11$ & $-31.57 \pm 2.04$ & $42.47 \pm 3.24$ & $74.04 \pm 4.22$ \\
ACPL_PF_O & $4.73 \pm 0.37$ & $5.73 \pm 0.32$ & $-17.57 \pm 1.61$ & $19.76 \pm 1.16$ & $37.33 \pm 0.61$ \\
\hline
\end{tabular}


indicating that maple veneer is considerably less prone to weather-induced structuring and cracking than beech veneer.

Marginal increase in $R_{q}$ from 4.04 to $6.67 \mu \mathrm{m}$ in case of FASY_PF_O and nearly no changes of the counterparts' roughness with maple surface (unexposed: $5.63 \mu \mathrm{m}$, exposed: $5.73 \mu \mathrm{m}$ ) clearly indicate the stabilizing effect of $\mathrm{PF}$ overlay films. The impact of MF films and MF/PF overlay combinations on surface topographical features of artificially weathered Compreg is under investigation and will be published in a separate contribution.

\section{Conclusion}

The study has shown that the weather-related surface degradation of Compreg with top veneers from European beech originates from initial cracking within large wood rays in longitudinal direction. Subsequent embrittlement, microcracking and stress whitening of the PF resin coating associated with gradual resin erosion from the top veneer surface is culminating in a distinct surface whitening, microstructuring and gloss reduction. Application of top veneers from European white birch and European maple substantially reduced the susceptibility of respective Compreg variants to cracking but did not prevent surface degradation. Since respective samples without overlay finish markedly changed their surface color, use of PF impregnated paper overlays significantly reduced discoloration reaching the lowest color change in case of using maple top veneers, but induced lower gloss retention indicating unwanted surface microstructuring. Conversely, application of MF overlays to specimens with top veneers from maple significantly reduced surface structuring and gloss reduction but led to an increased surface discoloration by light-induced darkening of originally bright Compreg types. Most promising effects that include simultaneous color and surface stabilization of Compreg surfaces were obtained combining both MF and PF impregnated overlay coatings and treatment of top veneers with MF impregnation resins. As a result, there are potential Compreg grades with enhanced weather resistance of the materials surface available that make its outdoor use even more sustainable.

Acknowledgements The authors are grateful to Dr. R. Emmler (IHD Dresden) for fruitful discussions and B. Stephanie (IHD Dresden) for conducting X-ray densitometry. H. Klüber and U. Widman (Pagholz Formteile GmbH, Germany) are kindly acknowledged for providing raw materials and giving valuable insights into the industrial Compreg production.

Funding Parts of this work were carried out within the project MF130036, financially supported via EuroNorm GmbH by the Federal Ministry of Economic Affairs and Energy within the innovation program INNO-KOM, based on a decision of the German Parliament.

\section{Compliance with ethical standards}

Conflict of interest On behalf of all authors, the corresponding author states that there is no conflict of interest.

Open Access This article is licensed under a Creative Commons Attribution 4.0 International License, which permits use, sharing, adaptation, distribution and reproduction in any medium or format, as long as you give appropriate credit to the original author(s) and the source, provide a link to the Creative Commons licence, and indicate if changes were made. The images or other third party material in this article are included in the article's Creative Commons licence, unless indicated otherwise in a credit line to the material. If material is not included in the article's Creative Commons licence and your intended use is not permitted by statutory regulation or exceeds the permitted use, you will need to obtain permission directly from the copyright holder. To view a copy of this licence, visit http://creativecommons.org/licenses/by/4.0/.

\section{References}

Bao M, Huang X, Zhang Y, Yu W, Yu Y (2016) Effect of density on the hygroscopicity and surface characteristics of hybrid poplar compreg. J Wood Sci 62(5):441-451

Baysal E, Degirmentepe S, Simsek H (2014) Some surface properties or thermallly modified Scots pine after artificial weathering. Maderas Ciencia y tecnología 16(3):355-364

Bicke S, Militz H (2015) Weathering stability of PF-treated veneer products from beech wood. In: Proc. of the 8th European congress of wood modification, Helsinki, Finland, pp 273-280

Biziks V, Bicke S, Militz H (2019) Penetration depth of phenol-formaldehyde (PF) resin into beech wood studied by light microscopy. Wood Sci Technol 53(1):165-176

Dunky M, Niemz P (2002) Holzwerkstoffe und Leime: Technologie und Einflussfaktoren (Wood-based materials and glues: technology and influencing factors). Springer, Berlin, pp 699-700 (in German)

EN 438-2 (2016) High-pressure decorative laminates (HPL) - sheets based on thermosetting resins (usually called laminates) - part 2: determination of properties. CEN, Brussels

EN ISO 2813 (2014) Paints and varnishes - determination of gloss value at $20^{\circ}, 60^{\circ}$ and $85^{\circ}$. CEN, Brussels

EN ISO 4892-2 (2013) Plastics - methods of exposure to laboratory light sources - part 2: xenon-arc lamps. CEN, Brussels

EN ISO 11664-4 (2008) Colorimetry - part 4: CIE 1976 L*a*b* colour space. CEN, Brussels

Evans PD, Michell AJ, Schmalzl KJ (1992) Studies of the degradation and protection of wood surfaces. Wood Sci Technol 26:151-163

Evans PD, Wallis AFA, Owen NL (2000) Weathering of chemically modified wood surfaces. Natural weathering of Scots pine acetylated to different weight gains. Wood Sci Technol 34:151-165

Evans PD, Kraushaar Gibson S, Cullis I, Liu C, Sèbe G (2013) Photostabilization of wood using low molecular weight phenol formaldehyde resin and hindered amine light stabilizer. Polym Degrad Stab 98:158-168

Faucheu J, Wood KA, Sung LP, Martin JW (2006) Relating gloss loss to topographical features of a PVDF coating. JCT Res 3(1):29-39

Gabrielli CP, Kamke FA (2010) Phenol-formaldehyde impregnation of densified wood for improved dimensional stability. Wood Sci Technol 44:95-104

Hansmann Ch, Deka M, Wimmer R (2005) Artificial weathering of wood surfaces modified by melamine formaldehyde resins. Holz Roh Werkst 64:198-203 
Hill CA (2006) Wood modification - chemical, thermal and other processes. Wiley, London

Hon DN-S, Minemura N (2001) Color and discoloration. In: Hon DN-S, Shiraishi N (eds) Wood and cellulosic chemistry. Marcel Dekker, New York, pp 385-442

Kollmann F (1942) Vergütete Hölzer und holzhaltige Bau- und Werkstoffe, Begriffe und Zeichen. Erläuterungen zum Normblatt DIN 4076 (Modified wood and wood-containing building and construction materials, terms and symbols. Explanations to the standard sheet DIN 4076). Holz Roh Werkst 5:41-59 (in German)

Kollmann F (1955) Technologie des Holzes und der Holzwerkstoffe (Technology of wood and wood-based materials), vol 2, 2nd edn. Springer, Berlin, pp 460-467 (in German)

Küch W (1939) Untersuchungen an Holz, Sperrholz und Schichthölzern im Hinblick auf ihre Verwendung im Flugzeugbau (Investigations on wood, plywood and laminated wood with regard to their use in aircraft construction). Holz Roh Werkst 2:257-272 (in German)

Küch W (1951) Über die Vergütung des Holzes durch Verdichtung seines Gefüges (About the modification of wood by compacting its structure). Holz Roh Werkst 9:305-317 (in German)

Niemz P, Wagenführ A (2012) Werkstoffe aus Holz. In: Taschenbuch der Holztechnik (Materials made of wood. In: Paperback of wood technology). Hanser Verlag, Leipzig, pp 127-259 (in German)

Oberhofnerová E, Pánek M, García-Cimarras A (2017) The effect of weathering on untreated wood surfaces. Maderas Ciencia y tecnología 19(2):173-184

Osterhold M, Glöckner P (2001) Influence of weathering on physical properties of clearcoats. Prog Org Coat 41(1-3):177-182

Passauer L, Prieto J, Müller M, Rössler M, Schubert J, Beyer M (2015) Novel color stabilization concepts for decorative surfaces of native dark wood and thermally modified timber. Prog Org Coat 89:314-322

Passauer L, Schubert J, Flade P, Peters J (2016) Weather resistance of transparent surfaces from compressed laminated wood impregnated with PF resin. Poster presentation, 10th European wood based panel symposium. October 6th-7th, Hamburg, Germany

Pilato L (2008) Resin chemistry. In: Pilato L (ed) Phenolic resins: a century of progress. Springer, Heidelberg, pp 41-92

Pizzi A (2003) Melamine-formaldehyde adhesives. In: Pizzi A, Mittal KL (eds) Handbook of adhesive technology, 2nd edn. Marcel Dekker, New York, pp 646-673

Rabek JF (1995) Polymer photodegradation. Mechanisms and experimental methods. Chapman \& Hall, London, pp 279-280

Ranta L, May H-A (1978) Zur Messung von Rohdichteprofilen an Spanplatten mittels Gammastrahlen (Measurement of bulk density profiles on chipboards using gamma rays). Holz Roh Werkst 36(12):467-474 (in German)

Reinprecht L, Mamoňová M, Pánek M, Kačík F (2018) The impact of natural and artificial weathering on the visual, colour and structural changes of seven tropical woods. Eur J Wood Prod 76:175-190

Richter C (2014) Overview of cracks/shake forms and causes. In: Wood characteristics. Description, causes, prevention, impact on use and technological adaptation. Springer, Cham, pp 199-208
Rivaton A, Lemaire J (1989) Photo-oxydation de résines phénoliques. (Photo-oxidation of phenolic resins). Makromol Chem 190:23112324 (in French)

Rowell RM (1999) Speciality treatments. In: Wood handbook. Wood as an engineering material. Gen. Tech. Rep. FPL-GTR-113. U.S. Department of Agriculture, Forest Service, Forest Products Laboratory, Madison, WI, pp 19.1-19.14

Schindelin J, Arganda-Carreras I, Frise E (2012) Fiji: an open-source platform for biological-image analysis. Nat Methods 9(7):676-682

Schulte C (1938) Herstellung und Verwendung von Lignofol-Zahnrädern (Production and use of lignofol gears). Holz Roh Werkst 1:391-392 (in German)

Seborg RM (1955) The application and properties of IMPREG. Ames For 42:9-13

Shams MI, Yano H (2004) Compressive deformation of wood impregnated with low molecular weight phenol formaldehyde (PF) resin II: effects of processing parameters. J Wood Sci 50:343-350

Shams MI, Yano H (2006) Compressive deformation of wood impregnated with low molecular weight phenol formaldehyde (PF) resin: effects of steam pretreatment. J Wood Sci 52:389-394

Shams MI, Yano H (2011) Compressive deformation of phenol formaldehyde (PF) resin-impregnated wood related to the molecular weight of resin. Wood Sci Technol 45:73-81

Shams MI, Yano H, Endou K (2004) Compressive deformation of wood impregnated with low molecular weight phenol formaldehyde (PF) resin I: effects of pressing pressure and pressure holding. J Wood Sci 50:337-342

Shams MI, Kagemori N, Yano H (2006) Compressive deformation of wood impregnated with low molecular weight phenol formaldehyde (PF) resin IV: species dependency. J Wood Sci 52:179-183

Stamm AJ, Seborg RM (1941) Resin treated, laminated, compressed wood . Trans Am Inst Chem Eng 37:385-397

Stamm AJ, Seborg RM (1955) Resin-treated, laminated, compressed wood (Compreg). FPL Report 1381, Forest Products Laboratory, United States Department of Agriculture

Thebault M, Müller U, Kandelbauer A, Zikulnig-Rusch E, Lammer H (2017) Factors influencing the processing and technological properties of laminates based on phenolic resin impregnated papers. Eur J Wood Prod 75:785-806

Thum A, Jacobi HR (1938) Die Biegefestigkeit von stahlbewehrtem Panzerholz (The bending strength of steel-reinforced Panzerholz). Holz Roh Werkst 1(9):335-339 (in German)

Wagenführ R (1996) Holzatlas (Wood atlas), 4th edn. Fachbuchverlag, Leipzig (in German)

Westin M, Sterley M, Rossi F, Hervé JJ (2009) Compreg-type products by furfurylation during hot-pressing. Wood Mater Sci Eng 4(1-2):67-75

Yano H, Hirose A, Inaba S (1997) High-strength wood-based materials. J Mater Sci 16:1906-1909

Publisher's Note Springer Nature remains neutral with regard to jurisdictional claims in published maps and institutional affiliations. 